\title{
Exocrine Pancreatic Secretion in Rats Treated with Reserpine after Stimulation with Pilocarpine, Dopamine, and Caerulein
}

\author{
DAVID MORTON, ANNE PARKER, PATRICIA ESTRADA, AND J. RICARDO MARTINEZ
}

Department of Child Health, University of Missouri, School of Medicine, Columbia, Missouri, USA

\begin{abstract}
Summary
Pancreatic juice was collected in vivo from control and reserpine-treted rats after stimulation with pilocarpine $(0.2 \mathrm{mg} / 100 \mathrm{~g}$ body weight), dopamine $(6-7 \mathrm{mg} / 100 \mathrm{~g}$ body weight), caerulein (90-100 pmole total dose) or with a combination of caerulein and secretin ( $6 \mathrm{u} / 100 \mathrm{~g}$ body weight) and the volume, amylase, bicarbonate and chloride outputs were compared. The results indicate that the secretory response to the three secretagogues was significantly reduced in the drug treated animals. Thus, the volumes of pancreatic juice were $57.0,60.5$, and $15.7 \%$ of those obtained in control rats after stimulation with, respectively, pilocarpine, dopamine, and caerulein. Amylase output was 63.8, 67.1, and 21.0\% and bicarbonate output was $29.9,46.8$, and $6.2 \%$ of those observed in untreated rats after the same stimulants. Fluid secretion increased in the treated animals to $71.3 \%$ of that of controls when both caerulein and secretin were administered together and amylase output became greater than in control rats $(151 \%)$. However, bicarbonate output was still $55.2 \%$ of that of controls with this combined stimulation. It is concluded that chronic reserpine administration impairs exocrine pancreatic secretion and that this effect involves both the acinar and ductal portions of the gland. This impairment involves the physiologic responses of these two segments of the glandular epithelium to both neural and hormonal stimulants. These findings suggest that the exocrine pancreatic disturbance in reserpine-treated rats may be similar to that observed in cystic fibrosis (CF), and because the treated rat has been proposed as a model for the human disease, they suggest the use of this model as a test system for the study of the pancreatic secretory abnormality in CF.
\end{abstract}

\section{Speculation}

Rats treated in a chronic fashion with reserpine secrete significantly smaller amounts of fluid, amylase, and bicarbonate in pancreatic juice than control animals, whether secretion is elicited by hormonal or neural stimulants. The abnormality in exocrine pancreatic function induced by the drug treatment involves, therefore, the acinar and ductal segments of the gland and is similar to the alteration seen in patients with CF.

Rats treated in a chronic fashion with reserpine show marked secretory disturbances in several exocrine glands which resemble those observed in patients with CF $(9,10,12,14)$. In the pancreas, the effect of the drug treatment is manifested by the secretion of smaller volumes of pancreatic juice in response to cholecystokinin and to secretin (12). The reduced response to these secretagogues is accompanied by changes in amylase and protein excretion and by a reduction in total bicarbonate output (12). The relationship between bicarbonate or chloride concentrations and the flow rate were also abnormal in the pancreatic juice of the treated animals.

Physiologically, exocrine pancreatic secretion is thought to occur by two separate and independently regulated mechanisms involving two distinct portions of the glandular epithelium. Thus, secretion of enzymes from acinar cells is regulated by both the cholinergic innervation and by cholecystokinin-pancreozymin (3, $7,8,11,13)$. Secretion of the water/electrolyte fraction of pancreatic juice is thought to take place in centroacinar and duct cells under the influence of secretin $(3,7,8,11,13)$. The results of the previous study on the pancreatic secretory response of reserpinetreated rats suggested, therefore, that the drug treatment affected the function of both acinar and duct cells and impaired their response to hormonal regulators.

In this investigation, a further analysis of the pancreatic secretory response in the reserpine-treated rat has been conducted by studying the volume of pancreatic juice, the excretion of bicarbonate and the excretion of amylase induced by neurohomoral mediators. In adition, the effects of the peptide caerulein have been investigated, by way of comparison with those of cholecystokinin and of the autonomic agents.

\section{MATERIALS AND METHODS}

Male albino rats of the Sprague Dawley strain were used. The treated group received seven daily doses of reserpine $(0.5 \mathrm{mg} / \mathrm{kg})$ by ip injection as previously described $(9,10)$. The ones used as untreated controls were housed in the same quarters with the drug treated ones and were kept for 7 days. All animals were allowed free access to water and to a standard pelleted diet but were deprived of food, but not water, during the last 24 hours before killing. On the 8 th day, they were anesthetized with an ip injection of sodium pentobarbital (6-8 mg/100 g body weight) and cannulae were inserted into the trachea and the jugular vein. The duodenal portion of the pancreas was exposed through a midline abdominal incision, the common bile duct was identified and 2-3 $\mathrm{mm}$ were carefully freed in its distal end in order to identify its entrance into the duodenum. A loose double ligature was passed around the free portion of the duct and a third one was looped at the distal end under $20 \mathrm{X}$ manigfication with a Leitz stereo dissecting microscope and a polyethylene cannula (Clay Adams PE 10) was inserted for 1-2 $\mathrm{mm}$ into the duct lumen. Spontaneous flow of bile-stained fluid began immediately. The hepatic end of the duct was then tied and the fluid flow decreased. This resting flow was allowed to continue until the fluid appearing at the tip of the cannula was clear. At this time, secretagogues were either injected or infused through the catheter placed in the jugular vein. In the second case, the stimulants were infused by using a constant infusion pump. Infusions were continued for approximatley 30 min, and pancreatic juice samples were collected at timed intervals during the period of stimulation and for 2.5-3.5 hr after the stimulation had ceased. All samples were collected under oil in preweighed microsample tubes and were kept in ice. The volume of pancreatic juice in each sample was estimated gravimetrically by reweighing the collection tubes. At the end of the entire collection period, the animal was killed by air insufflation into the thoracic cavity. The pancreas was carefully removed and weighed 
to the nearest $\mathrm{mg}$ in a top loading balance. Bicarbonate concentrations were measured in $10 \mu \mathrm{l}$ aliquots in a Natelson microgasometer; chloride concentrations were determined in a Buchler chloride titrator and amylase concentrations by a colorimetric method that compares the difference in absorbance of a starchiodine complex in the sample with that of a blank (Harleco Co., Gibbstown, NJ). An amylase unit is defined as the amount of enzyme that will hydrolyze $10 \mathrm{mg}$ of starch in $30 \mathrm{~min}$.

The secretagogues used in this study were: 1) Pilocarpine nitrate. This agent was injected at a rate of $0.1 \mathrm{mg} / \mathrm{min}$ until a total dose of $0.2 \mathrm{mg} / 100$ body weight was obtained. The injections were completed, therefore, in 3-6 min. 2) Dopamine hydrochloride, a neurohumoral agent that has been shown to cause the secretion of a secretin-like pancreatic juice in dogs (5). A solution of $25 \mathrm{mg}$ / $\mathrm{ml}$ was prepared and infused at the rate of $18 \mu \mathrm{l} / \mathrm{min}$. 3) Caerulein. A solution of this peptide was made in saline bicarbonate and was infused at the rate of $3.1 \mathrm{pmole} / \mathrm{min}$. 4) Secretin. A solution of purified secretin was made in saline bicarbonate and was infused until a dose of $6 \mathrm{u} / 100 \mathrm{~g}$ body weight was achieved. In experiments where the two latter drugs were used in combination, the secretin was dissolved first and then caerulein was added to the desired concentration. Pilocarpine, dopamine, and caerulein were all purchased from Sigma Chemical Co., St. Louis, MO. Purified secretin was purchased from the Gastrointestinal Hormone Laboratory of the Karolinska Institut, Stockholm, Sweden. Statistical analysis of the result was done by calculating mean values and SD of the mean and by using Student's $t$ test.

\section{RESULTS}

\section{SECRETORY RESPONSE}

Table 1 shows the total volume of pancreatic juice secreted and the maximum flow rate attained with each of the various secretagogues used in these experiments. In control animals, the largest volume and highest flow rates were attained after stimulation with both caerulein and secretin. Caerulein alone caused the secretion of a smaller volume of juice and the maximum flow rates attained under these conditions of stimulation were the lowest in the entire series of experiments. Pilocarpine was more effective than dopamine in eliciting secretion and the maximum flow rate attained with the former was also higher.

The secretory response from the pancreas of reserpine-treated rats was characterized by the following 1) significantly lower volumes of pancreatic juice were secreted in all cases; and 2) the maximum flow rates attained were also significantly smaller than those attained by normal rats. In fact, the response to caerulein in fasted, reserpine-treated animals was extremely poor (Table 1).

Table 1 also shows the duration of the secretory response in both types of animals. In general, the response to dopamine, pilocarpine, caerulein, and to the caerulein-secretin combination lasted for approximately $3 \mathrm{hr}$. The response from reserpine-treated rats was also long lasting, except in the case of caerulein alone which caused a significantly shorter secretory response in these animals when compared to that of control rats.

\section{SECRETION OF AMYLASE, BICARBONATE, AND CHLORIDE}

In order to further characterize the secretory response, the total output of amylase, bicarbonate, and chloride were calculated in all the expriments by adding the amount present in all the samples of pancreatic juice collected under each specific mode of stimulation.

Table 2 shows the results for both control and treated animals. In control animals, amylase output was highest after stimulation with pilocarpine and smallest after stimulation with dopamine. Caerulein and the combination caerulein-secretin caused the secretion of intermediate amounts of amylase. Amylase output was significantly smaller $(P<0.01)$ in the juice of reserpine-treated rats, except when the caerulein-secretin combination was used. In this case, amylase output was greater in the juice of the treated animals.

The output of bicarbonate from the pancreas of control rats in experiments where dopamine was used as the stimulant was

Table 1. Secretory response (fasted rats)

\begin{tabular}{|c|c|c|c|c|c|}
\hline Sectetagogue & Treatment & $\mathrm{N}$ & $\begin{array}{l}\text { Duration of } \\
\text { response } \\
\text { (min) }\end{array}$ & $\begin{array}{c}\text { Total } \\
\text { volume } \\
(\mathrm{mg})\end{array}$ & $\begin{array}{c}\text { Maximum } \\
\text { flow rate } \\
(\mathrm{mg} / \mathrm{min} \cdot \mathrm{gm})\end{array}$ \\
\hline \multirow[t]{2}{*}{ Dopamine } & Control & 10 & $188 \pm 13$ & $124 \pm 20$ & $1.449 \pm 0.217$ \\
\hline & Reserpine & 11 & $161 \pm 20$ & $75 \pm 10$ & $0.928 \pm 0.117$ \\
\hline \multirow[t]{2}{*}{ Pilocarpine } & Control & 12 & $175 \pm 14$ & $151 \pm 22$ & $2.130 \pm 0.260$ \\
\hline & Reserpine & 16 & $171 \pm 13$ & $86 \pm 8$ & $1.666 \pm 0.277$ \\
\hline \multirow[t]{2}{*}{ Caerulein } & Control & 8 & $199 \pm 10$ & $83 \pm 17$ & $0.541 \pm 0.083$ \\
\hline & Reserpine & 8 & $96 \pm 30$ & $13 \pm 5$ & $0.103 \pm 0.041$ \\
\hline Caerulein & Control & 7 & $203 \pm 4$ & $289 \pm 5$ & $5.508 \pm 1.258$ \\
\hline+ secretin & Reserpine & 8 & $215 \pm 5$ & $206 \pm 42$ & $3.086 \pm 0.350$ \\
\hline
\end{tabular}

Table 2. Secretion of amylase, bicarbonate, and chloride (fasted rats)

\begin{tabular}{|c|c|c|c|c|}
\hline Stimulant & Treatment & $\begin{array}{c}\text { Amylase } \\
\left(\text { Units } \times 10^{5}\right) \\
\text { total }\end{array}$ & $\begin{array}{c}\mathrm{HCO}_{3}^{-} \\
\text {(millivolumes) } \\
\text { total }\end{array}$ & $\begin{array}{l}\text { Chloride (nEq) } \\
\text { total }\end{array}$ \\
\hline \multirow[t]{2}{*}{ Dopamine } & Control & $1754.3 \pm 466.5$ & $172.4 \pm 32.6$ & $8935.0 \pm 1856.0$ \\
\hline & Reserpine & $1176.9 \pm 333.1$ & $80.6 \pm 19.1$ & $5372.0 \pm 970.0$ \\
\hline \multirow[t]{2}{*}{ Pilocarpine } & Control & $6876.1 \pm 964.1$ & $159.6 \pm 26.9$ & $13909.0 \pm 2292.0$ \\
\hline & Reserpine & $4390.0 \pm 441$ & $47.9 \pm 5.7$ & $7022.5 \pm 1122.5$ \\
\hline \multirow[t]{2}{*}{ Caerulein } & Control & $3207.9 \pm 776.3$ & $90.6 \pm 20.4$ & $6228.0 \pm 2166.0$ \\
\hline & Reserpine & $674.1 \pm 309$ & $5.6 \pm 3.4$ & \\
\hline Caerulein & Control & $3131.5 \pm 635.7$ & $442.4 \pm 98.5$ & $24817.5 \pm 4244.7$ \\
\hline+ secretin & Reserpine & $4735.4 \pm 917.3$ & $244.0 \pm 74.9$ & $15073.1 \pm 2255.7$ \\
\hline
\end{tabular}


substantial and similar to that caused by purified secretin (12). Bicarbonate output was also significant in the juice of normal rats after stimulation with pilocarpine, but was much smaller when caerulein was used as the stimulant. A very large output of bicarbonate, significantly higher $(P<0.01)$ than those observed in the other experiments, was obtained in the juice of control rats when caerulein and secretin were given simultaneously. Bicarbonate output was significantly smaller $(P<0.005)$ in the pancreatic juice of reserpine-treated rats in all cases.

Total chloride output was highest in the pancreatic juice of control rats after stimulation with the caerulein-secretin combination. It was also significant after pilocarpine stimulation. Both dopamine and caerulein caused the secretion of smaller amounts of chloride. As in the case of bicarbonate, chloride output was significantly reduced in the pancreatic juice of reserpine-treated rats regardless of the type of stimulant used.

\section{DISCUSSION}

The results of this study demonstrate that the secretory capacity of the exocrine pancreas is significantly reduced in rats treated in a chronic fashion with reserpine. This alteration is manifested by the secretion of smaller volumes of pancreatic juice at reduced rates of flow and by reductions in the output of amylase, bicarbonate, and chloride after stimulation with pilocarpine, dopamine, and caerulein.

Because the drug-induced alteration involves the secretion of amylase and of fluid and bicarbonate, it can be asumed that it affects the two major secretory portions of the pancreas namely, the acinar and centroacinar (duct) cells, which are thought to be involved, respectively, in the secretion of the macromolecular and electrolyte (aqueous) fractions of pancreatic juice $(3,7,8,11)$. A similar conclusion was reached in a previous study (12) which demonstrated a reduced response to both CCK and secretin. The present results indicate that the reduction in pancreatic secretory capacity after reserpine administration is a generalized effect involving not only the response to the regulatory hormones, but also to neurohumoral agents and to stimulatory peptides.

Except in the case of caerulein, the reduced secretory response from the pancreas of reserpine-treated rats does not appear to be related to a shorter time course (Table 1). It can be concluded, therefore, that the drug treatment affects the mechanism of secretion itself and that it impairs the response of both acinar and centroacinar cells to physiologic stimuli. The mechanism through which the drug treatment alters these responses can not be ascertained from the present results. The stimulus-secretion coupling mechanism in the exocrine pancreas is a complex process (11) involving not only an interaction between the neural and hormonal controls of acinar cells $(6,11)$ and possible interactions between the hormonal regulation of acinar and duct cells (3), but also a complex sequence of cellular events leading to secretion (11). The toxic effect of reserpine administration could involve, therefore, alterations in secretagogue metabolism, in their interaction with cell receptors or in the intracellular metabolic pathways underlying secretion.

The observation that both amylase and fluid secretion increased in reserpine-treated animals when caerulein and secretin were administered simultaneously suggests that the reduced enzyme release can be overcome, at least partially, by improved fluid secretion. This finding does not clearly indicate, however, if this is merely a washout phenomenon secondary to an enhanced fluid secretion from centroacinar cells by secretin, or whether it results from an improved acinar cell function due to cooperative effects of the two secretagogues on these cells, as previously shown for cholecystokinin (CCK) and secretin (3). Secretin has been shown to cause ultrastructural changes in acinar cells (1) and it has been proposed that acinar and duct cells not only have their own specific receptors but also those of the other cell type $(3,11)$. The results of these experiments favor the possibility of an improved acinar cell function as a result of mutual cooperation between caerulein and secretin, because bicarbonate output was still significantly reduced under these conditions of stimulation (Table 2).

A reduction in the electrolyte fraction of pancreatic juice, alone or in combination with an overproduction of the organic fraction, was proposed as a possible explanation of the abnormal pancreatic secretory response in patients with CF (4). The results of these experiments suggest that similar changes are present in the pancreas of the reserpine-treated rat. The pancreatic disturbance in the animal model can be used, therefore, as a test system for further studies aimed at understanding the pathogenesis of the pancreatic secretory disturbance in $\mathrm{CF}$.

\section{CONCLUSIONS}

Rats treated in a chronic fashion with reserpine secrete a smaller volume of pancreatic juice and smaller amounts of amylase and bicarbonate than untreated control animals, whether secretion is elicited by neurohumoral agents (pilocarpine, dopamine) or by a stimulatory peptide (caerulein) which mimics the action of CCK. Because these secretory responses are also reduced in the reserpine-treated rat after stimulation with secretin and with CCK, it was concluded that the drug treatment impairs the response of both acinar and ductal segments of the glandular epithelium to their physiologic regulators and that this effect causes an alteration in pancreatic function which resembles that which has been described in patients with CF. As such, the exocrine pancreatic abnormality induced by reserpine can be used as a model system for the study of pathogenic mechanisms in this disease.

\section{REFERENCES AND NOTES}

1. Blomfield, J., and Seltree, P. J.: Ultrastructural studies of pancreatic secretory mechanisms. CF Club Abstracts, 18: 25 (1977).

2. Erspamer V., and Melchiorri, P.: Active polypeptides of the amphibian skin and their synthetic avalogs. Pure Appl. Chem., 35: 463 (1973).

3. Grossman, M. I.: Hormone-hormone and vagus-hormone interactions on gastric acid secretion. In: S. Anderson: Frontiers in Gastrointestinal Hormone Research (Alnquist and Wiksell, Stockholm 1973) pp 203.

4. Hadorn, B., Johansen, P. G., and Anderson, C. M.: Exocrine pancreatic function in cystic fibrosis. In: D. Lawson: Proc. 5th International Cystic Fibrosis Conference, (Churchill College, Cambridge, 1969) p. 55.

5. Hashimoto, K., Satoh, S., and Takeuki, O.: Effect of dopamine on pancreatic secretion in the dog. Brit. J. Pharmacol. 43: 739 (1971).

6. Konturek, S. J., Tasler, J., and Obtulowick, W.: Effect of caerulein and endogenous cholecystokinin on urecholine-induced gastric acid and pancreatic protein secretion in dogs. Gastroenterology, 65: 235 (1973).

7. Mangos, J. A., and McSherry, M. R.: Micropuncture Study of Excretion of water and electrolytes by the pancreas. Ames. J. Physiol., 221; 496 (1971).

8. Mangos, J. A., McSherry, N. A., Nousia-Arvanitakis, S., and Schilling, R. Transductal fluxes of anions in the rat pancreas. Proc. Soc. Exp. Biol. Med., 146: 231 (1974).

9. Martinez, J. R., Adelstein, E. A., Quissell, D. O., and Barbero, G. J.: The chronically reserpinized rat as a possible model for cystic fibrosis: I Submaxillary gland morphology and ultrastructure. Pediatr. Res., 9: 463 (1975).

10. Martinez, J. R., Adshead, P. C., Quissell, D. O., and Barbero, G. J. The chronically reserpinized rat as a possible model for cystic fibrosis: II Composition and celioenhibitory effects of submaxillary saliva. Pediatr. Res, 9: 47 (1975).

11. Meldolesi, J.: Regulation of pancreatic Exocrine secretion. Pharmacol. Res. Comm., 8: 1 (1976).

12. Perlmutter, J. and Martinez, J. R: The chronically reserpinized rat as a possible model for cystic fibrosis: VII Alterations in the secretory response to cholecystokinin and to secretin from the pancreas in vivo. Pediatr. Res., 12: 188 (1978).

13. Sewel, W. A., and Young, J. A.: Secretion of electrolytes by the pancreas of the anesthetized rat. J. Physiol., 252: 379 (1975).

14. Thompson, F E., Quissell, D. O., Williams, C. H. and Martinez, J. R.: The chronically reserpinized rat as a possible model for cystic fibrosis. IV The protein composition of pulmonary lavage fluid. Pediatr. Res., 10: 632 (1976).

15. D. Morton was the recipient of a National Foundation (March of Dimes) Student Science Fellowship., A. Parker and P. Estrada were Student Fellows during the course of this study.

16. This research was supported by grants from the Cystic Fibrosis Foundation and the United States Public Health Service. (AM18150).

17. Received for publication October 17, 1978.

18. Accepted for publication January 30, 1979. 